\title{
Child Maltreatment Assessment by using Belief Rule based Expert System
}

\author{
Ferdous Ara \\ Lecturer \\ Department of Computer Science \& Engineering \\ BGC Trust University Bangladesh
}

\author{
Nazmun Nahar \\ Department of Computer Science \& Engineering \\ University of Chittagong
}

\begin{abstract}
Child maltreatment or abuse is a global public health issue. Child maltreatment is when a parent or caregiver causes injury, emotional harm or risk of serious harm to a child. Maltreated children rely on the eyes, ears and voices of their communities to help protect them from damage. Maltreatment child requires help or protection. This paper presents the accuracy of belief rule-based method over traditional primary assessment method using indicators (sign, symptoms and clue) of child maltreatment. The warning indicators of child maltreatment vary from child to child. They have different ways of coping with maltreatment, and the indicators often depend on each child's characteristics and environment. Recognizing the indicators of child maltreatment is important. Various uncertainties such as ignorance, incompleteness, randomness, and imprecision exist in the indicators of child maltreatments. The traditional assessment system which is carried by an expert, cannot give dependable results. In contrast, the belief rule-based expert system can adapt to the uncertain indicators to assess child maltreatment. The knowledge base of this method is based on the expert opinion. The results obtained from the proposed system have shown that the expert system's results are more accurate and reliable than traditional system.
\end{abstract}

\section{Keywords}

Child Maltreatment, Child Abuse, Uncertainty, Expert System, Belief Rule Base.

\section{INTRODUCTION}

Child maltreatment has a lengthy history. Children have been subject to negatively treated by their parents or other adults since presumably the beginning of time. For centuries the laws failed to protect children from maltreatment. Child maltreatment can occur in a child's home, or in the organizations, schools or communities the child interacts with. The categories of child maltreatment are neglect, physical, psychological/emotional abuse, and sexual abuse. In fact, research shows child maltreatment due to the problems including substance maltreatment, intimate partner violence, teenage pregnancy, anxiety, depression, suicide, diabetes, ischemic heart disease, sexually transmitted diseases, smoking, and obesity [1]. The World Health Organization (WHO) defines child maltreatment and child maltreatment as "all forms of or other exploitation, resulting in actual or potential harm to the child's health, survival, development or dignity in the context of a relationship of responsibility, trust or power"[2]. Child Maltreatment Prevention and Treatment Act in The United States federal defines Child maltreatment and neglect as, at minimum, "any recent act or failure to act on the part of a parent or caretaker which results in death, serious physical or emotional harm, sexual maltreatment or exploitation" or "an act or failure to act which presents an imminent risk of serious harm [3]. Leeb [4] uses the term child maltreatment to refer to both acts of commission (maltreatment), which include "words or overt actions that cause harm, potential harm, or threat of harm to a child", and acts of omission (neglect), meaning "the failure to provide for a child's basic physical, emotional, or educational needs or to protect a child from harm or potential harm".

Child maltreatment is a major public health problem which is associated with a broad range of negative health outcomes across the lifespan [5]. Psychological and health problems are increased among children and adolescents exposed to Child Maltreatment. Mental health problems include internalizing conditions such as depression, anxiety and post-traumatic stress disorder and also externalizing conditions like as antisocial behavior, substance maltreatment and suicidal behavior. There is also increased risk of low academic achievement developmental problems and relationship problems with parents and neighbors. They often experience more social problems and perform less well in school. There are no universally accepted definitions for any maltreatment. Child maltreatment has long-term effects which are painful and damaging to mental condition. Victims are at higher potential risk of becoming violent adult offenders. Experts predict that violence toward children will continue to rise and to have a significant impact on the social system. Efforts should be made by all citizens to intervene and stop child maltreatment. Survivors of sexual maltreatment tend to harbor feelings of low self-esteem and extreme depression and often experience a higher than normal incidence of substance maltreatment and eating disorders. Child maltreatment is a global problem with serious life-long consequences. International studies reveal that $20 \%$ of women and $5-10 \%$ of men report being sexually maltreatment as children, while 25 $50 \%$ of all children report being physically maltreatment. Additionally, many children are subject to emotional maltreatment (sometimes referred to as psychological maltreatment) and to neglect. Every year, there are an estimated 41000 homicide deaths in children below 15 years of age (WHO) [6].In South Asian countries due to high population density, illiteracy, poverty, caste system and landlessness, rural-urban migration, lack of economic opportunities, population growth, political instability and weak implementation of legal provisions the issues of child labor and these are somewhat responsible for child maltreatment and child sexual exploitation are high in this region. The knowledge that we gain with the different studies in this research cluster is used to design and test the effectiveness of interventions aimed at reducing the risk of child maltreatment. We also study the effectiveness of intervention-based assessments of parenting skills when children face an out of home placement decision. The ultimate goal of this research cluster is to identify the lives of children living in dysfunctional families by using belief rule-based expert system to measure the probability of child whether he or she is at maltreatment or not. Child maltreatment is not always obvious, and many children are too young or too 
scared to tell his nearest one what is happening to them. Children, especially younger, more vulnerable children, are often unaware that what is happening to them is maltreatment. Sometimes, it takes a caring adult - like a teacher, child care worker, pastor, family member or neighbor - to recognize that something is not right in the child's life. Many signs and symptoms, both physical and behavioral, can be associated with child although a child who shows no maltreatment, signs may also have been maltreated. However, it is important to note that the presence of one or more of these signs or symptoms does not confirm that child maltreatment has occurred. There is no single behavioral sign or symptom that warrants, on its own, a diagnosis of child maltreatment, as most of the behavioral signs are non-specific. Although it is often performed in clinical practice, the diagnostic value of a screening physical examination to detect maltreatment in children without prior suspicion has not been reviewed. This article is an examination of child maltreatment by using belief rule-based expert system.

The determination of accurate degree of child maltreatment is difficult for the expert, and hence, there is a risk of having incomplete information to conclude child maltreatment assessment. By using Rule-base appropriate $\mathrm{KB}$, creation is not possible to remove the uncertainty problem is. In the rulebase forward chaining and backward chaining lakes the procedure to calculate the activation weight of a rule as well as to aggregate the rules in a rule base. Hence, the inference procedure of rule-base is not so strong. Belief rule-based expert System can handle uncertainty that exists in the indicators of child maltreatment. By applying Belief Rulebase, the expert system can handle uncertainty. For this reason, the knowledge base of the expert system has been developed using belief rule base. Evidential reasoning approach has been considered as an inference engine for the expert system. It has been observed that the proposed model is effective and can assess the maltreated child better than manual system (usually carried out by a specialist) regarding accuracy.

The remaining part of the paper is organized as follows. Section two presents Belief rule-based expert systems methodology to assess child maltreatment. Section three describes the design and implementation of the BRB expert system. Section four presents the experimental results and discussion, while Section five concludes the paper.

\section{BELIEF RULE-BASED EXPERT SYSTEMS METHODOLOGY TO ASSESS CHILD MALTREATMENT}

BRBES use the belief rule, which is the extended form of conventional IF-THEN rule to represent the uncertain indicators in child maltreatment. Knowledge-base and inference procedures are the two components of an expert system. Belief rule-base is used to represent the domain knowledge under uncertainty. Inference procedures of BRBES consist of input transformation, rule activation weight calculation, belief update and rule aggregation using evidential reasoning [7]. The knowledge representation and reasoning procedures are presented below, which are essential to develop the BRBES to assess the child maltreatment.

Ignorance, incompleteness, vagueness and imprecision are the uncertainties that observe with the indicators in assessing child maltreatment. Neglect, physical \& psychological abuse and sexual abuse are common child maltreatment sign and symptoms. Indicator "delayed in development" and" lack of basic needs" are often expressed by the parent or caregiver by using linguistic terms which are subjective; hence the expression is ambiguous, vague and imprecise. Therefore, it cannot be measured with $100 \%$ accuracy. Ignorance and vagueness are the types of uncertainties, associated with "depression" and "frightened". For this indicator, the information from the parent or caregiver of the maltreated child often contains inadequate facts which are the clear indication of their ignorance about child maltreatment and also found inconsistency regarding describing the symptoms in similar cases with the different parent or caregiver.

\subsection{Representation of Domain Knowledge}

A belief rule is the extension of traditional IF-THEN rule, where a belief structure is used in the consequent part. Antecedent part of the belief rule consists of one or more antecedent attributes with associated referential value and consequent part consists of one consequent attribute. Eq. (1) represents an example of belief rule.

$$
\mathrm{R}_{\mathrm{k}}:\left\{\begin{array}{c}
\mathrm{IF} \\
\left(\mathrm{A}_{1} \text { is } \mathrm{A}_{1}^{\mathrm{k}}\right) \wedge\left(\mathrm{A}_{2} \text { is } \mathrm{A}_{2}^{\mathrm{k}}\right) \wedge \ldots \wedge\left(\mathrm{A}_{\mathrm{T}_{\mathrm{k}}} \text { is } \mathrm{A}_{\mathrm{T}_{\mathrm{k}}}^{\mathrm{k}}\right) \\
\text { THEN } \\
\left\{\left(\mathrm{C}_{1}, \bar{\beta}_{\mathrm{k} 1}\right),\left(\mathrm{C}_{2}, \bar{\beta}_{\mathrm{k} 2}\right), \ldots,\left(\mathrm{C}_{\mathrm{N}}, \bar{\beta}_{\mathrm{kN}}\right)\right\},\left(\left(\sum_{\mathrm{n}=1}^{\mathrm{N}} \bar{\beta}_{\mathrm{kn}} \leq 1\right)\right) \\
\text { with rule weight } 0 \leq \theta_{\mathrm{k}} \leq 1, \\
\text { and attribute weight } \delta_{1}^{\mathrm{k}}, \delta_{2}^{\mathrm{k}}, \ldots, \delta_{\mathrm{T}}^{\mathrm{k}} \geq 0 \\
\text { satisfying } \sum_{\mathrm{i}=1}^{\mathrm{T}_{\mathrm{k}}} \delta_{\mathrm{i}}^{\mathrm{k}}=1
\end{array}\right.
$$

Where, $A_{1}, A_{2}, \ldots, A_{T_{k}}^{k}, T_{k} \in\{1,2, \ldots, T\}, \quad$ are the antecedent attributes used in the k-th rule. $A_{i}^{k} \square\left\{A_{i 1}, A_{i 2}, \ldots, A_{i j_{i}}\right\}$ is the referential value of antecedent attribute. $C_{1}, C_{2}, \ldots, C_{N}$ are the referential values of the consequent attribute while $\bar{\beta}_{\mathrm{ki}}$ is the belief degree to which $\mathrm{C}_{\mathrm{i}}$ is believed to be true. If $\sum_{\mathrm{i}=1}^{\mathrm{N}} \bar{\beta}_{\mathrm{ki}}=$ 1 , the belief rule is said to be complete, otherwise it is incomplete.

$$
R k:\left\{\begin{array}{l}
\text { IF "neglect" is "M" AND "sexual abuse" is "L" } \\
\text { AND "physical \& physiological abuse" is "M" } \\
\text { THEN "child maltreatment" is H }(0.20), \\
\text { M (0.80), L (0.00) }
\end{array}\right.
$$

where (High, 0.20), (Medium, 0.80), (Low, 0.00) are the referential values along with belief degrees associated with the consequent attribute, which is "child maltreatment" as

\begin{tabular}{|c|c|c|c|c|c|c|}
\hline \multirow{2}{*}{$\begin{array}{l}\text { Sl. } \\
\text { No }\end{array}$} & \multirow{2}{*}{$\begin{array}{c}\text { Input } \\
\text { antecedent }\end{array}$} & \multirow{2}{*}{$\begin{array}{l}\mathbf{I} \\
\mathbf{n} \\
\mathbf{p} \\
\mathbf{u} \\
\mathbf{t}\end{array}$} & \multirow{2}{*}{$\begin{array}{c}\begin{array}{c}\text { Expert } \\
\text { belief }\end{array} \\
\left(\mathbf{E}_{\mathrm{i}}\right)\end{array}$} & \multicolumn{3}{|c|}{ Referential value } \\
\hline & & & & $\mathbf{H}$ & $\mathbf{M}$ & $\mathbf{L}$ \\
\hline 1. & $\begin{array}{l}\text { Lack of } \\
\text { basic needs }\end{array}$ & $\mathrm{L}$ & 0.2 & 0.00 & 0.40 & 0.60 \\
\hline 2. & Indifferent & $\mathrm{H}$ & 0.8 & 0.60 & 0.40 & 0.00 \\
\hline
\end{tabular}
elaborated in Eq. (1). The degree of belief as distributed with "High" is $20 \%$, with "Medium" is $80 \%$ and with "Low" is $0 \%$. Since the sum of the belief degrees is $1(0.20+0.80+$ 0.00 ), the belief rule is said to be complete.

Table I: Input transformation into referential values 


\begin{tabular}{|c|c|c|c|c|c|c|}
\hline & $\begin{array}{l}\text { to the } \\
\text { children }\end{array}$ & & & & & \\
\hline 3. & $\begin{array}{l}\text { Delayed in } \\
\text { development }\end{array}$ & $\mathrm{L}$ & 0.2 & 0.00 & 0.40 & 0.60 \\
\hline 4. & $\begin{array}{l}\text { Exhibit } \\
\text { sexual } \\
\text { knowledge }\end{array}$ & $\mathrm{H}$ & 0.9 & 0.79 & 0.20 & 0.00 \\
\hline 5. & $\begin{array}{l}\text { Difficulty } \\
\text { walking or } \\
\text { sitting }\end{array}$ & $\mathrm{M}$ & 0.1 & 0.00 & 0.19 & 0.80 \\
\hline 6. & $\begin{array}{l}\text { Non- } \\
\text { accidental } \\
\text { injury }\end{array}$ & $\mathrm{L}$ & 0.2 & 0.00 & 0.40 & 0.60 \\
\hline 7. & $\begin{array}{l}\text { Non- } \\
\text { accidental } \\
\text { injury }\end{array}$ & $\mathrm{H}$ & 1.0 & 1.00 & 0.00 & 0.00 \\
\hline 8. & Depression & $\mathrm{L}$ & 0 & 0.00 & 0.00 & 1.00 \\
\hline 9. & Frightened & $\mathrm{L}$ & 0 & 0.00 & 0.00 & 1.00 \\
\hline 10. & $\begin{array}{l}\text { Delayed in } \\
\text { development }\end{array}$ & M & 0.3 & 0.00 & 0.60 & 0.40 \\
\hline 11. & Depression & $\mathrm{L}$ & 0 & 0.00 & 0.00 & 1.00 \\
\hline 12. & $\begin{array}{l}\text { Lack of } \\
\text { basic needs }\end{array}$ & $\mathrm{H}$ & 0.5 & 0.00 & 1.00 & 0.00 \\
\hline
\end{tabular}

\subsection{Inference Procedure of Belief Rule Base}

Input transformation consists of the distribution of the input value of an antecedent attribute over its different referential values by applying Eq. (3).

$H\left(I_{i}, \epsilon_{i}\right)=\left\{\left(A_{i j}, \beta_{i j}\right), j=1, \ldots, j i\right\}, i=1, \ldots, T_{k}$

$\mathrm{H}$ is the evaluation of the degree of belief which is set to the input value. $A_{i j}$ ( $i$-th value) is the $j$-th referential value of the input Ii. $\beta_{\mathrm{ij}}$ is the degree of belief or the matching degree of the input data to the referential value $\mathrm{A}_{\mathrm{ij}}$ of an antecedent attribute. The input data on the antecedent attributes are collected from the child or from the domain expert in linguistic terms such as "High," "Medium" and "Low." The degree of belief $\epsilon_{i}$ is assigned from linguistic terms by considering the view of domain expert's heuristics. Then $\epsilon_{\mathrm{i}}$ is transformed into the degree of belief associated with the various referential values $A_{i j}[\operatorname{High}(H)$, Medium $(M)$, and Low (L)]. The utility value $h_{i j}$ can be assigned to $A_{i j}$. For example, "High" referential value can be assigned utility value as $\mathrm{h}_{\mathrm{i} 3}=1.0$, "Medium" as $\mathrm{h}_{\mathrm{i} 2}=0.5$ and "Low" as $\mathrm{h}_{\mathrm{i} 1}=$ 0 . The input transformation procedure is carried out by using Eq. (4) and (5).

IF $\mathrm{h}_{\mathrm{i} 3} \geq \epsilon_{\mathrm{i}} \geq \mathrm{h}_{\mathrm{i} 2}$ THEN $\beta_{\mathrm{i} 2}=\mathrm{h}_{\mathrm{i} 3}-\epsilon_{\mathrm{i}} / \mathrm{h}_{\mathrm{i} 3}-\mathrm{h}_{\mathrm{i} 2}, \quad \beta_{\mathrm{i} 3}=\left(1-\beta_{\mathrm{i} 2}\right)$,

$\beta_{\mathrm{il}}=1-\sum_{j=0}^{2} \beta_{\mathrm{ij}}$

IF $h_{\mathrm{i} 2}>\epsilon_{\mathrm{i}} \geq \mathrm{h}_{\mathrm{i} 1}$ THEN $\beta_{\mathrm{i} 1}=\mathrm{h}_{\mathrm{i} 2}-\epsilon_{\mathrm{i}} / \mathrm{h}_{\mathrm{i} 2}-\mathrm{h}_{\mathrm{i} 1}, \quad \beta_{\mathrm{i} 2}=\left(1-\beta_{\mathrm{i} 1}\right)$,

$\beta_{\mathrm{i} 3}=1-\sum_{j=0}^{2} \beta_{\mathrm{ij}}$

\subsubsection{Calculation of Activation Weights}

Combined matching degree can be calculated by using Eq. 6 . $\alpha_{k}=\prod_{i=1}^{T_{k}}\left(\alpha_{i}^{k}\right)^{\bar{\delta}_{i}^{k}}, \bar{\delta}_{i}^{k}=\frac{\delta_{i}^{k}}{\max _{\mathrm{i}=1, \ldots, T_{k}}^{k}\left\{\delta_{i}^{k}\right\}}$
So that $0 \leq \bar{\delta}_{i}^{k} \leq 1$. where, $\delta_{i}^{k}\left(\mathrm{i}=1, \ldots ., \mathrm{T}_{\mathrm{k}}\right)$ is the relative weight of the $\boldsymbol{i}$-th antecedent attribute in the $\boldsymbol{k}$-th belief rule.The rule activation weight is calculated by using Eq. 7 .

$\mathcal{W}_{k}=\left\{\theta_{k} \alpha_{k}\right\}\left\{\sum_{i=1}^{L} \theta_{i} \alpha_{i}\right\}$

Where, $\theta_{k}$ is the relative weight of the $k$-th rule; $\mathrm{L}$ is the total number of belief rule in the belief rule-base. When $\mathcal{W}_{k}$ of a rule is zero then it has no impact in the BRB while it is " 1 " then its important is high.

\subsubsection{Belief degree update}

Update belief degrees [7] to possible consequents in the BRB based on the input information using following formula:

$\beta_{k i}=\bar{\beta}_{k i} \frac{\sum_{t=1}^{T_{k}}\left(\tau(k, t) \sum_{j=1}^{J_{i}} \alpha_{t j}\right)}{\sum_{t=1}^{T_{k}} \tau(k, t)}$

Where, $\tau(\mathrm{k}, \mathrm{t})=\left\{\begin{array}{c}1, \text { ifisusedindefining } R_{k}\left(t=1, \ldots, T_{k},\right) \\ \text { or } \\ 0, \text { otherwise }\end{array}\right.$

Here, $\overline{\beta_{i k}}$ is the original belief degree while $\overline{\beta_{i k}}$ is the updated belief degree. The original belief degree updated if any ignorance noticed.

\subsubsection{Inference using evidential reasoning}

In order to obtain the aggregated value of the referential values of the consequent attribute, based on the input data of the antecedent attributes, either recursive or analytical evidential reasoning (ER) algorithms as shown in equation (9) can be applied [8];[9].

$\beta_{j}=\frac{\mu \times\left[\prod_{k=1}^{L}\left(\omega_{k} \beta_{k j}+1-\omega_{k} \sum_{j=1}^{N} \beta_{k j}\right)-\prod_{k=1}^{L}\left(1-\omega_{k} \sum_{j=1}^{N} \beta_{k j}\right)\right]}{1-\mu \times\left[\prod_{k=1}^{L}\left(1-\omega_{k}\right)\right]}$,

Where, $\mathrm{j}=1,2, \ldots, \mathrm{N}$

with $\quad \mu=\left[\sum_{j=1}^{N} \prod_{k=1}^{L}\left(\omega_{k} \beta_{k j}+1-\omega_{k} \sum_{j=1}^{N} \beta_{k j}\right)-\right.$ $\left.(N-1) \times \prod_{k=1}^{L}\left(1-\omega_{k} \sum_{j=1}^{N} \beta_{k j}\right)\right]^{-1}$

The combined result or output generated by ER is represented by $\left\{\left(C_{1}, \beta_{1}\right),\left(C_{2}, \beta_{2}\right),\left(C_{3}, \beta_{3}\right), \ldots \ldots \ldots\left(C_{N}, \beta_{N}\right)\right\}$, where $\beta_{j}$ is the final belief degree attached to the $j$-th referential value $C_{j}$ of the consequent attribute $\mathrm{C}$, which is obtained after all activated rules in the BRB are combined by using ER. This output can be converted into a crisp/numerical value [as shown in equation (10)] by assigning a utility score to each referential value of the consequent attributes.

$H\left(A^{*}\right)=\sum_{j=1}^{N} \mathrm{u}\left(C_{j}\right) \beta_{j}$

Where, $H\left(A^{*}\right)$ is the expected score expressed as a numerical value and $u\left(C_{j}\right)$ is the utility score of $\mathbf{j}$-th referential value.

\section{SYSTEM ARCHITECTURE}

BRBES presented in this paper follows three-layer architecture, consisting of web-based interface, application and database management layers as shown in Figure1.

This interface has been developed by integrating various web technologies such as Javascript, Jquery, HTML and CSS. The application layer has been developed by using PHP. The database management layer, which consists of clinical data and knowledge-base, developed by using MySQL. 


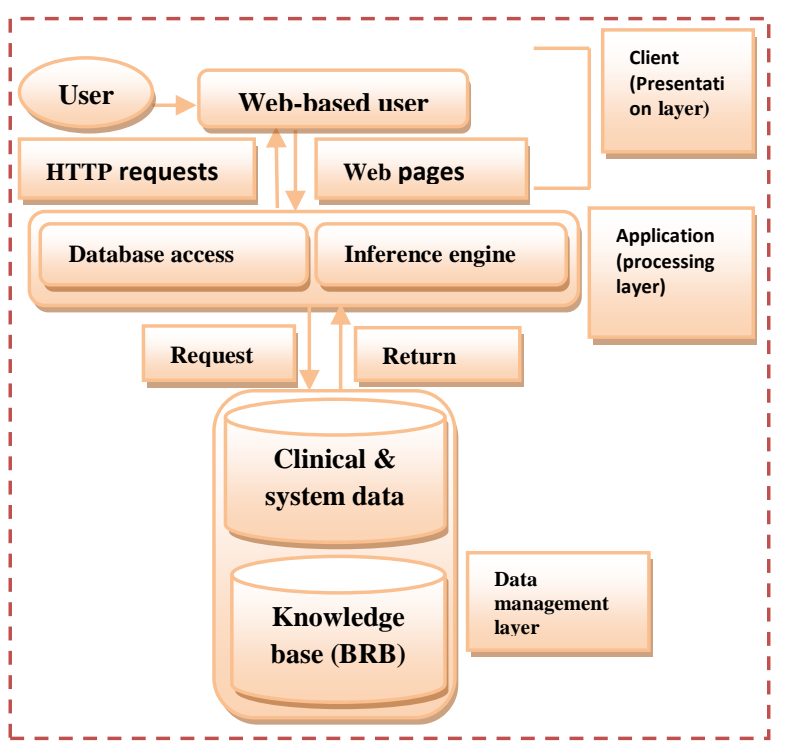

Fig 1: System architecture of the child maltreatment suspicion system.

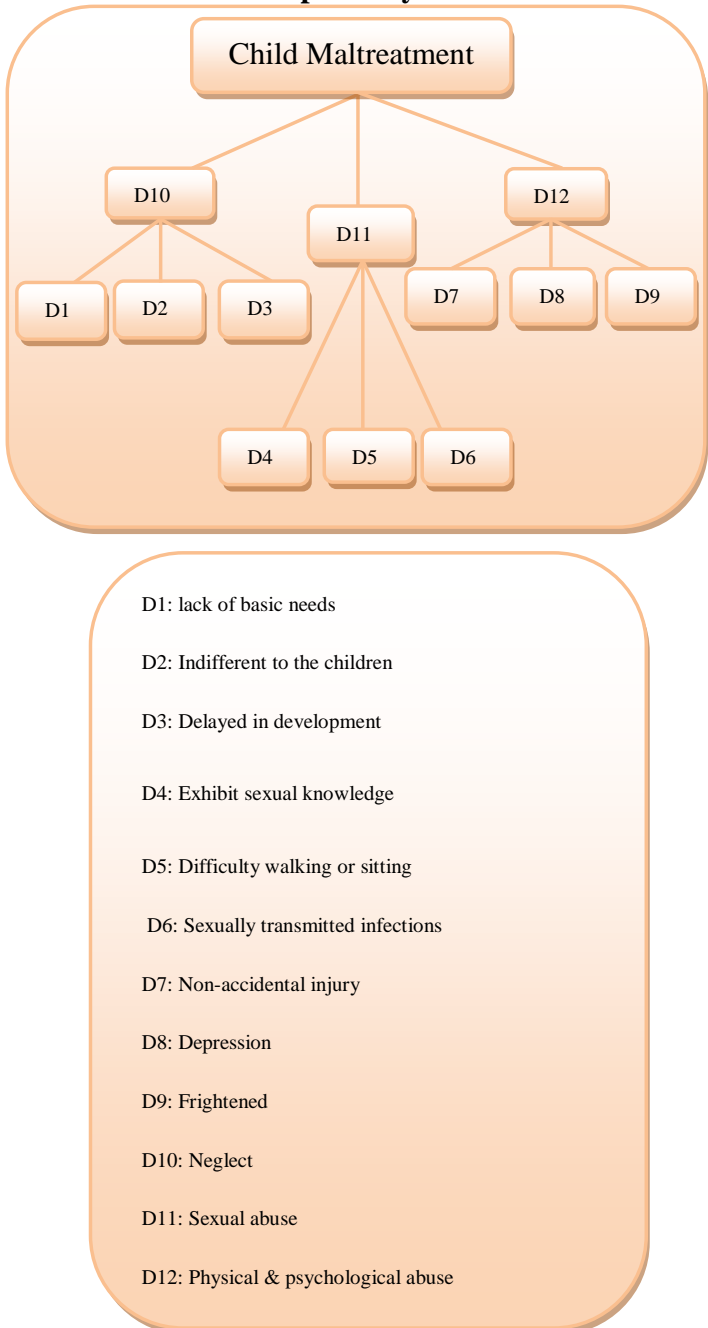

Fig 2: The BRB framework for child maltreatment assessment

\subsection{System Components}

In this section the child maltreatment knowledge base, BRBESs inference method and its interface are discussed.

Table II: Initial belief rule base for "Neglect BRB"

\begin{tabular}{|c|c|c|c|c|c|c|c|}
\hline \multirow{3}{*}{$\begin{array}{l}\text { Rule } \\
\text { ID }\end{array}$} & \multirow{3}{*}{$\begin{array}{l}\text { Rule } \\
\text { Weig } \\
\text { ht }\end{array}$} & \multicolumn{3}{|c|}{ IF } & \multirow{2}{*}{\multicolumn{3}{|c|}{$\begin{array}{c}\text { THEN } \\
\text { Neglect }\end{array}$}} \\
\hline & & \multirow[t]{2}{*}{ D1 } & \multirow[t]{2}{*}{ D2 } & \multirow[t]{2}{*}{ D3 } & & & \\
\hline & & & & & $\mathbf{H}$ & M & $\mathbf{L}$ \\
\hline R1 & 1 & $\mathrm{H}$ & $\mathrm{H}$ & $\mathrm{H}$ & 1.0 & 0.0 & 0.0 \\
\hline R2 & 1 & $\mathrm{H}$ & $\mathrm{H}$ & $\mathrm{M}$ & 0.6 & 0.4 & 0.0 \\
\hline R3 & 1 & $\mathrm{H}$ & $\mathrm{H}$ & $\mathrm{L}$ & 0.8 & 0.0 & 0.2 \\
\hline $\mathrm{R} 4$ & 1 & $\mathrm{H}$ & M & $\mathrm{H}$ & 0.6 & 0.4 & 0.0 \\
\hline R5 & 1 & $\mathrm{H}$ & M & M & 0.2 & 0.8 & 0.0 \\
\hline R6 & 1 & $\mathrm{H}$ & $\mathrm{M}$ & $\mathrm{L}$ & 0.0 & 0.3 & 0.7 \\
\hline R7 & 1 & $\mathrm{H}$ & $\mathrm{L}$ & $\mathrm{H}$ & 0.4 & 0.0 & 0.6 \\
\hline R8 & 1 & $\mathrm{H}$ & $\mathrm{L}$ & $\mathrm{M}$ & 0.5 & 0.3 & 0.2 \\
\hline R9 & 1 & $\mathrm{H}$ & $\mathrm{L}$ & $\mathrm{L}$ & 0.3 & 0.0 & $\begin{array}{l}0.7 \\
\end{array}$ \\
\hline R10 & 1 & $\mathrm{M}$ & $\mathrm{H}$ & $\mathrm{H}$ & 0.2 & 0.8 & 0.0 \\
\hline R11 & 1 & $\mathrm{M}$ & $\mathrm{H}$ & $\mathrm{M}$ & 0.6 & 0.2 & 0.2 \\
\hline R12 & 1 & $\mathrm{M}$ & $\mathrm{H}$ & $\mathrm{L}$ & 0.5 & 0.3 & 0.2 \\
\hline R13 & 1 & $\mathrm{M}$ & $M$ & $\mathrm{H}$ & 0.2 & 0.0 & 0.8 \\
\hline R14 & 1 & $\mathrm{M}$ & $\mathrm{M}$ & $\mathrm{M}$ & 0.0 & 1.0 & 0.0 \\
\hline R15 & 1 & $\mathrm{M}$ & $\mathrm{M}$ & $\mathrm{L}$ & 0.0 & 0.6 & 0.4 \\
\hline R16 & 1 & $\mathrm{M}$ & $\mathrm{L}$ & $\mathrm{H}$ & 0.8 & 0.0 & 0.2 \\
\hline R17 & 1 & $\mathrm{M}$ & $\mathrm{L}$ & $\mathrm{M}$ & 0.0 & 0.7 & 0.3 \\
\hline R18 & 1 & $\mathrm{M}$ & $\mathrm{L}$ & $\mathrm{L}$ & 0.0 & 0.4 & 0.6 \\
\hline R19 & 1 & $\mathrm{~L}$ & $\mathrm{H}$ & $\mathrm{H}$ & 0.6 & 0.3 & 0.2 \\
\hline R20 & 1 & $\mathrm{~L}$ & $\mathrm{H}$ & $\mathrm{M}$ & 0.5 & 0.3 & 0.2 \\
\hline R21 & 1 & $\mathrm{~L}$ & $\mathrm{H}$ & $\mathrm{L}$ & 0.2 & 0.0 & 0.8 \\
\hline R22 & 1 & $\mathrm{~L}$ & $\mathrm{M}$ & $\mathrm{H}$ & 0.5 & 0.3 & 0.2 \\
\hline R23 & 1 & $\mathrm{~L}$ & M & $\mathrm{M}$ & 0.0 & 0.8 & 0.2 \\
\hline R24 & 1 & $\mathrm{~L}$ & M & $\mathrm{L}$ & 1.0 & 0.0 & 0.0 \\
\hline R25 & 1 & $\mathrm{~L}$ & $\mathrm{~L}$ & $\mathrm{H}$ & 0.4 & 0.0 & 0.6 \\
\hline R26 & 1 & $\mathrm{~L}$ & $\mathrm{~L}$ & $\mathrm{M}$ & 0.0 & 0.3 & 0.7 \\
\hline R27 & 1 & $\mathrm{~L}$ & $\mathrm{~L}$ & $\mathrm{~L}$ & 0.0 & 0.0 & 1.0 \\
\hline
\end{tabular}

\subsubsection{Child maltreatment initial facts}

The initial facts responsible for child maltreatment are neglect (D10), sexual abuse (D11), and physical \& physiological abuse (D12).Sub-rule base neglect (D10) consist of lack of basic needs (D1), indifferent to the children (D2), and delayed in development (D3) whereas sexual abuse(D11) formed by, exhibit sexual knowledge (D4), difficulty walking or sitting (D5), and sexually transmitted infections (D6). On the other hand, physical \& physiological abuse (D12) is formed by nonaccidental injury (D7), depression (D8), and frightened (D9). These indicators are antecedent attributes of the different rules of belief rule base. For these indicators, the input data are taken from the maltreated child or the physicians as shown in Table 1. After then, this input data are converted into the belief of the domain expert. From Esq. (4) and (5), the expert belief is distributed over each referential value of an antecedent attribute, e.g., the input for antecedent attribute "Non-accidental injury" is collected from the maltreated child as "High" and expert belief against this is found as "1." This belief is then allotted over each referential value of this antecedent attribute as shown in Table 1. Child maltreatment affects children in different ways, so not all children will have all these indicators. Some children may have only mild indicators, while others may have a wider range of more severe indicators. 


\subsubsection{Knowledge base of BRBES}

A belief rule base schema has been formulated to build the knowledge base for the BRBES as shown in Figure 2. A BRB can be constructed in four ways such as extracting belief rules from expert knowledge, extracting belief rules by examining historical data, using the previous rule bases if available, and random rules without any pre-knowledge. The initial BRB has been constructed in this paper by the domain expert knowledge. The necessary indicators to determine the child maltreatment suspicion is shown in Figure 2. This BRB framework represents three BRBs, namely neglect (D10), sexual abuse (D11), and physical \& physiological abuse (D12). The "neglect BRB", "sexual abuse BRB", and "physical \& physiological BRB" are consist of three antecedent attributes each with three referential values. Therefore, these three BRB each comprises 27 rules. The "child maltreatment suspicions BRB" has three antecedent attributes with three referential values each; hence it comprises 27 rules. It is assumed that all rules and all antecedent attributes have equal weight. The initial belief degrees allocated to the referential values of the consequent attribute of a belief rule has been carried out by taking opinions of specialists. The referential values for each consequent attribute consist of High (H), Medium (M) and Low (L).

R1: IF "lack of basic needs" is "H" AND "indifferent to the children" is " $\mathrm{H}$ " AND "delayed in development" is " $\mathrm{H}$ " THEN "neglect BRB" is $\mathrm{H}(0.80), \mathrm{M}(0.20), \mathrm{L}(0.00)$.

\subsubsection{Inference engine using ER approach}

Evidential reasoning (ER) algorithm is used in the inference engine of this BRBES as discussed in Section 2.2. Inference engine first reads indicators data either from the maltreated child or the domain expert. Then these data are converted into matching degree by using Eq. (6) and activation weight of each rule is calculated by using Eq. (7). Belief degrees are updated if needed by employing Eq. (8) and at the last step rules are aggregated by using Eq. (9).

\subsubsection{System interface}

The graphical user interface of this system is shown in the following figures. Figure 5 allows the capturing of the data related to the indicators of child maltreatment as well as the displaying of the BRBESs results.

\section{BRB Expert System to Assess of Child Maltreatment}

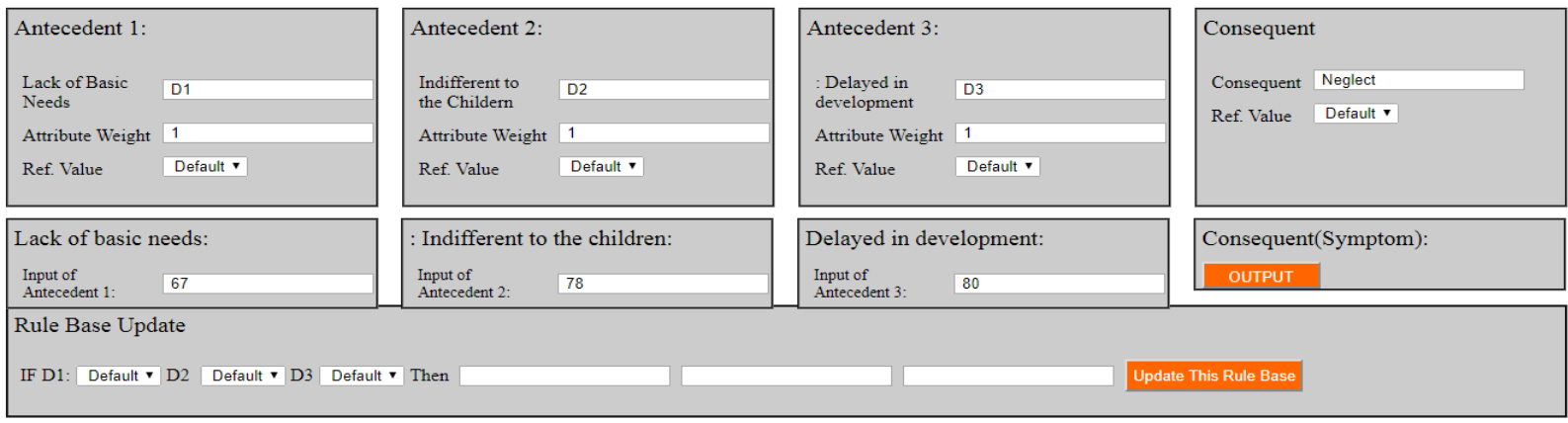

Fig 3: Snapshot (1) of the "neglect BRB"

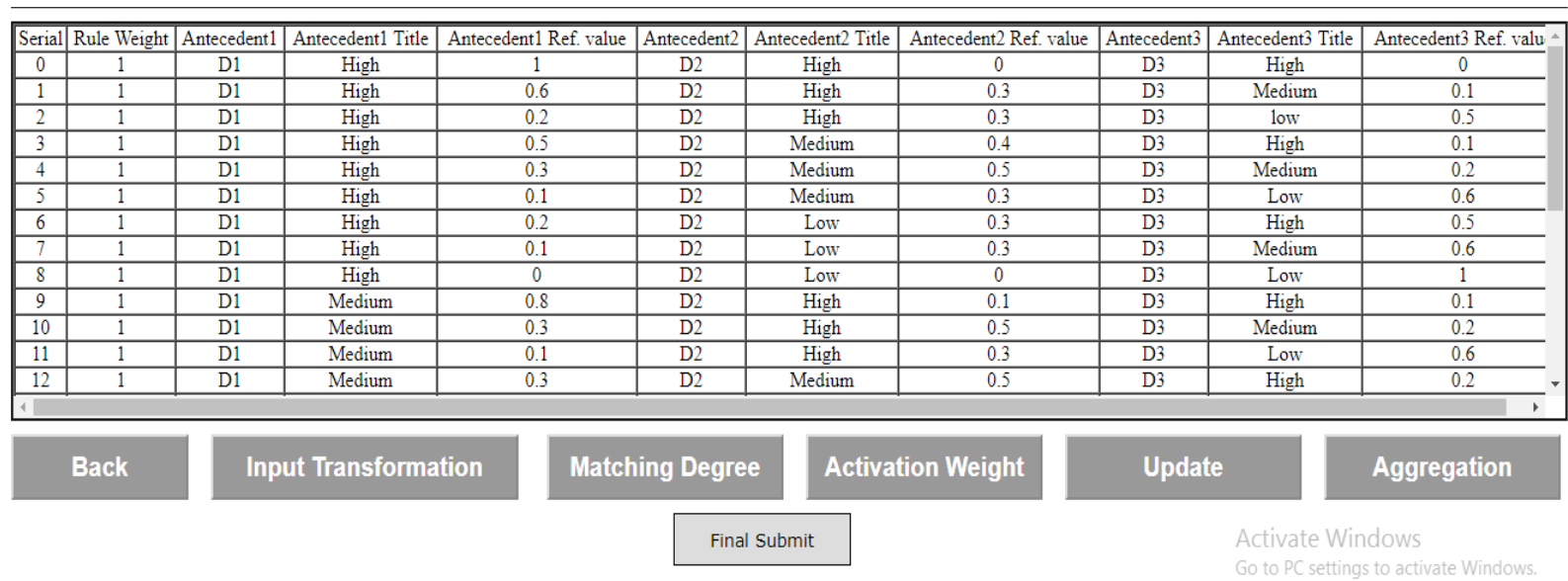

Fig 4: Snapshot (2) of the "neglect BRB" 


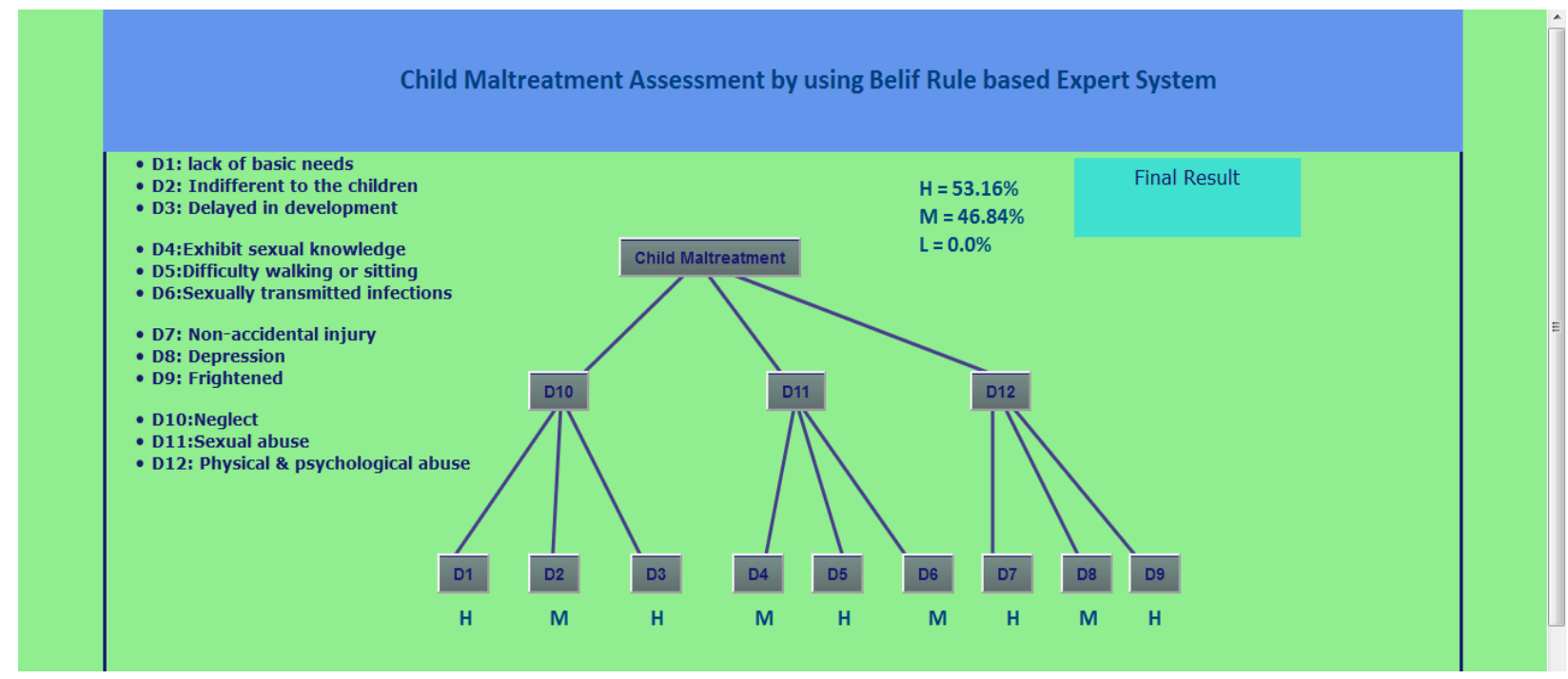

Fig 5: Interface of the BRB expert system

For example, Figure 5 outputs for the input data (D1 = "High," D2 = "Medium," D3 = "High," D4 = "Medium," D5 = "High," D6 = "Medium," D7 = "High," D8 = "Medium," D9 = "High,"). Figure 5 also illustrates the overall assessment of child maltreatment suspicion which is $\mathrm{H}(53.16 \%), \mathrm{M}$ (46.84\%), L $(0.0 \%)$. This is transformed into a numerical value by using Eq. (10), which is $76.58 \%$.

\section{RESULTS AND DISCUSSION}

The dataset consists of 70 data which were gathered from the maltreatment child in Bangladesh. If the expert's opinion on the level of child maltreatment is higher than $50 \%$, then the outcome is considered as one otherwise zero and this data has been viewed as the baseline is shown in Column 7 of Table III. Table III presents the data of 15 maltreated children out of 70. It illustrates the collected data on the three attributes of a maltreated child. Table III also shows the BRBES result (Column 5), and expert opinion (Column 6) on the level of child maltreatment suspicion for the same data. The benchmark data is recorded in column 7 .

Table III. Child maltreatment assessment by BRBES and Experts opinion

\begin{tabular}{|c|c|c|c|c|c|c|}
\hline \multirow[b]{2}{*}{$\begin{array}{l}\text { Id. } \\
\text { (1) }\end{array}$} & \multicolumn{3}{|c|}{ Indicators } & \multicolumn{3}{|c|}{ Result } \\
\hline & $\begin{array}{c}\text { D10 } \\
\text { (2) }\end{array}$ & $\begin{array}{c}\text { D11 } \\
\text { (3) }\end{array}$ & $\begin{array}{c}\text { D12 } \\
\text { (4) }\end{array}$ & $\begin{array}{l}\text { BRBE } \\
\text { S } \\
\text { Output } \\
(\%) \\
(5)\end{array}$ & $\begin{array}{l}\text { Expert } \\
\text { Opinion } \\
(\%) \\
(6)\end{array}$ & $\begin{array}{l}\text { Be } \\
\text { nch } \\
\text { ma } \\
\text { rk } \\
(7)\end{array}$ \\
\hline 1. & $\mathrm{H}$ & $\mathrm{M}$ & $\mathrm{H}$ & 80.26 & 81 & 1 \\
\hline 2. & $\mathrm{H}$ & $\mathrm{H}$ & $\mathrm{H}$ & 84.77 & 82 & 1 \\
\hline 3. & $\mathrm{M}$ & $\mathrm{M}$ & $\mathrm{L}$ & 45.18 & 41 & 0 \\
\hline 4. & $\mathrm{H}$ & $M$ & $\mathrm{M}$ & 65.25 & 45 & 0 \\
\hline 5. & $\mathrm{M}$ & M & $\mathrm{H}$ & 64.13 & 46 & 0 \\
\hline 6. & $\mathrm{H}$ & $\mathrm{H}$ & $\mathrm{H}$ & 84.05 & 65 & 1 \\
\hline 7. & $\mathrm{~L}$ & $\mathrm{~L}$ & $\mathrm{H}$ & 45.45 & 48 & 0 \\
\hline 8. & $\mathrm{~L}$ & $\mathrm{M}$ & $\mathrm{H}$ & 65.35 & 45 & 1 \\
\hline 9. & $\mathrm{H}$ & $\mathrm{H}$ & $\mathrm{H}$ & 95.25 & 70 & 1 \\
\hline 10. & $\mathrm{M}$ & $M$ & $\mathrm{H}$ & 58.05 & 50 & 1 \\
\hline 11. & $\mathrm{H}$ & $\mathrm{H}$ & $\mathrm{H}$ & 85.18 & 67 & 1 \\
\hline 12. & $\mathrm{H}$ & $\mathrm{L}$ & $\mathrm{M}$ & 74.67 & 70 & 1 \\
\hline 13. & $\mathrm{H}$ & $\mathrm{H}$ & $\mathrm{H}$ & 85.18 & 77 & 1 \\
\hline
\end{tabular}

\begin{tabular}{|l|l|l|l|l|l|l|}
\hline 14. & $\mathrm{M}$ & $\mathrm{H}$ & $\mathrm{H}$ & 69.86 & 45 & 1 \\
\hline 15. & $\mathrm{M}$ & $\mathrm{H}$ & $\mathrm{L}$ & 65.32 & 52 & 1 \\
\hline
\end{tabular}

ROC curve has its benefit in demonstrating assessment performances as it can be used to summarize the accuracy of an investigation with a single number by calculating the area under the curve (AUC). This method is considered to measure the reliability of BRBES in comparison with expert opinion. The accuracy of a system to assess the level of suspicion of the child maltreatment can be estimated by calculating the Area Under Curve (AUC) [10]; [11]. Figure 6 illustrates the ROC curves plotted for BRBES data and Expert Opinion. The ROC curve plotted by the blue line in this figure is associated with the results generated by the BRBES with AUC of $0.955(95 \%$ confidence intervals $0.850-1.000)$. The green line in ROC curve is obtained against the expert's opinion, and its AUC is 0.886 (95\% confidence intervals $0.714-1.000$ ).

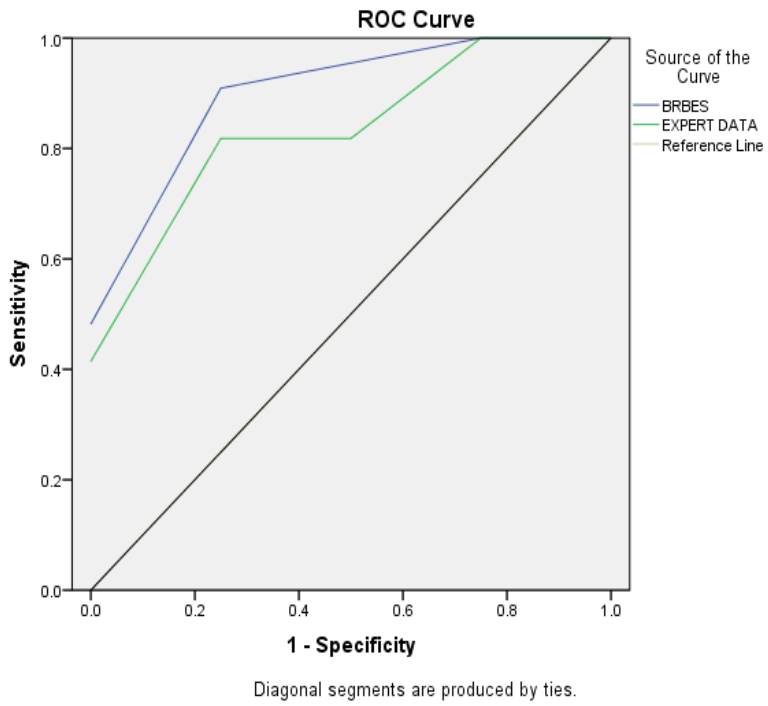

Fig 6: ROC Curves Comparing the Result of BRBES and Expert Data

Table IV summarizes the above results associated with BRBES, Expert Opinion. From Figure 6 as well as from Table 
IV it can be observed that AUC of Expert Opinion is less than from the BRBES.

Table IV: Reliability comparison among BRBES and Expert Data Area Under the Curve

\begin{tabular}{|c|c|c|c|c|c|}
\hline \multirow{2}{*}{$\begin{array}{l}\text { Test } \\
\text { Result } \\
\text { Variable } \\
\quad \text { (s) }\end{array}$} & \multirow{2}{*}{ Area } & \multirow{2}{*}{$\begin{array}{l}\text { Std. } \\
\text { Error }\end{array}$} & \multirow{2}{*}{$\begin{array}{c}\text { Asy } \\
\text { mpto } \\
\text { tic } \\
\text { Sig }\end{array}$} & \multicolumn{2}{|c|}{$\begin{array}{l}\text { Asymptotic 95\% } \\
\text { Confidence } \\
\text { Interval }\end{array}$} \\
\hline & & & & $\begin{array}{l}\text { Lower } \\
\text { Bound }\end{array}$ & $\begin{array}{l}\text { Upper } \\
\text { Bound }\end{array}$ \\
\hline BRBES & .955 & .054 & .009 & .850 & 1.000 \\
\hline $\begin{array}{l}\text { EXPERT } \\
\text { DATA }\end{array}$ & .886 & .088 & .026 & .714 & 1.000 \\
\hline
\end{tabular}

The reason for this is that during the interviewing with the experts it has been seen that they are not conscious of the uncertainty issues related to the indicators of child maltreatment. The SPSS 16.20 is used to draw the ROC curve and calculation the AUC of this curve.

\section{CONCLUSIONS}

Child maltreatment assessment BRBES can provide the better result than the traditional expert. The reason for this is that expert is unable to consider various types of uncertainties such as ambiguity, imprecision, randomness and ignorance, those are associated with the indicators of the child maltreatment during the assessment process. In future research, we will solve the limitations and will try for further development of a better expert system. The system will be build by using Genetic Algorithm (GA) and Artificial Neural Network (ANN) so that a comparison can be done among GA, ANN and BRBES. Assessment performance of the expert system can be significantly improved after training the BRB through accumulated clinical cases. For preciously detection of child maltreatment proposed system will be beneficiary. By using online base PHP platform, anyone from anywhere in the world can detect child maltreatment. It is very important to identify a child victim. Detection the early trauma to future development is crucial to assisting the victim. A child who has been maltreatment requires support and treatment as early as possible. The longer a child continues to be maltreatment the less likely make a full recovery. Parents should always be conscious of any unexpected changes in the child's body and behavior. We hope by using this system anyone able to assess the level of child maltreatment. If a child is maltreated by a parent, caregiver, or another person in a custodial role (e.g., clergy, coach, teacher), it's become a duty to call the police or local child welfare agency.

\section{REFERENCES}

[1] Mercy, J. A., \& Saul, J. 2009. Creating a healthier future through early interventions for children. JAMA: Journal of the American Medical Association, 301, pg 1-3.

[2] World Health Organization. 2016. Child maltreatment. Fact sheet. Reviewed September 2016. [Online]. Available:

[3] http://www.who.int/mediacentre/factsheets/fs150/en/

[4] U.S. Department of Health \& Human Services. 2015. Child maltreatment. Children's Bureau, Administration on Children, Youth and Families. Available: https://americanspcc.org/wpcontent/uploads/2014/03/2015-Child-Maltreatment.pdf

[5] Leeb, R.T., Paulozzi, L.J., Melanson, C., Simon, T.R., Arias, I. 2008. Child Maltreatment Surveillance: Uniform Definitions for Public Health and Recommended Data Elements, Version 1.0, Centers for Disease Control and Prevention National Center for Injury Prevention and Control Atlanta, Georgia.

[6] Gilbert, R., Widom, C.S., Browne, K., Fergusson, D.M., Elspeth, W., \& Janson, S. 2009. Child Maltreatment 1: Burden and consequences of child maltreatment in highincome countries. The Lancet. 373, pg 68-81.

[7] World Health Organization. 2017. Child deaths from abuse and neglect. CFCA Resource Sheet- October 2017. [Online]. Available: https://aifs.gov.au/cfca/publications/child-deaths-abuseand-neglect.

[8] Yang, J.B., Liu, J., Wang, J., Sii, H.S., \& Wang, H.W. 2006. Belief rule-base inference methodology using the evidential reasoning approach RIMER. IEEE Trans Syst Man Cybern Part A Syst Hum, 36 (2), pg 266-285.

[9] Yang, J.B. 2001. Rule and utility based evidential reasoning approach formulation attribute decision analysis under uncertainties. Eur J Oper Res, 131 (1), pg $31-61$.

[10] Yang, J.B., \& Sen, P.1994. A general multi-level evaluation process for hybrid MADM with uncertainty. IEEE Trans Syst Man Cybern, 24(10), pg 1458-1473.

[11] Metz, C.E. 1978. Basic principles of ROC analysis. Semin. Nucl. Med. 8(4), pg 283-298.

[12] Hanley, J.A. 1988. The robustness of the "Binormal" assumptions used in fitting ROC curves. Med Decis Making, 8(3), pg 197-203. 